\title{
IMPACT OF MEASUREMENT METHODS ON THE DEVELOPMENT OF FREE-FLOW SPEED ESTIMATION MODEL FOR BASIC SEGMENT EXPRESSWAYS IN MALAYSIA
}

\author{
Leong L.V. \\ School of Civil Engineering, Universiti Sains Malaysia, \\ Engineering Campus, 14300 Nibong Tebal, Penang, Malaysia

\section{Muhammad H.} \\ Traffic Engineer, Perunding Trafik Klasik Sdn. Bhd., L13A-01-02, Level 13A, PJX-HM Shah \\ Tower, No. 16A, Persiaran Barat, 46050 Petaling Jaya, Selangor, Malaysia
}

\begin{abstract}
This study aims to assess the impact of several selected free-flow speed measurement methods that are deemed suitable for basic segment expressways in Malaysia. Free-flow speed is defined as a speed where the driver can travel comfortably with their own desired speed that is within seed limit, without being constrained by physical conditions of the roadway or obstructed by other road users. Data were collected at 17 sites across Peninsular Malaysia during peak and off-peak periods. Three different criteria which includes linear speed-density relationship graphs, the average speed of vehicles recorded during low to moderate traffic volume and the average speed of vehicles with headway threshold of 8 seconds were adopted in this study. Subsequent analyses to develop and assess the free-flow speed estimation models were conducted by performing multiple linear regression and performance indicator analyses. Results indicated that the model developed using the free-flow speed measured based on headway threshold of 8 seconds is the most favorable model. The model was deemed as the best fitted model based on the highest $R 2$ value of 0.8908 , and the total score of 10 calculated based on five performance indicators. Application of the developed free-flow speed estimation model based on local traffic conditions can contribute significantly to improving the accuracy of free-flow speed values and, better estimation of capacity and level-of-service for basic segment expressways in Malaysia.
\end{abstract}

Key words: Free-flow speed, basic segment expressways, headway, flow rate, performance indicators.

Cite this Article: Leong L.V. and Muhammad H., Impact of Measurement Methods on the Development of Free-Flow Speed Estimation Model for Basic Segment Expressways in Malaysia, International Journal of Advanced Research in Engineering and Technology, 10(4), 2019, pp. 113-122

http://iaeme.com/Home/issue/IJARET?Volume $=10 \&$ Issue $=4$ 
Leong L.V. and Muhammad H.

\section{INTRODUCTION}

Basic segment is a type of facility under the expressways categories in which it is outside of the influence area of ramp or weaving areas of an expressway. In Malaysia, there are 27 expressways with the total length of 1,630 km. The longest expressway in Malaysia is NorthSouth Expressway (NSE) with the total length of $775 \mathrm{~km}$ running from Bukit Kayu Hitam in Kedah near to Malaysia-Thai border to Johor Bharu at the southern portion of Peninsular Malaysia and to Singapore. This expressway acting as the 'backbone' of the west coast of the peninsula and provides a faster alternative to the old Federal Route, thus reducing travelling time between various towns and cities.

Free-flow speed can be defined as the desired speed of a vehicle at which the drivers can travel comfortably within the speed limit without being interfered by other vehicles and not constrained by control devices. Alternatively, free-flow speed can also be defined as the hypothetical average speed of vehicles when traffic volumes on the actual roadway conditions are low to moderate, which is up to $1,300 \mathrm{pcu} / \mathrm{h}$ [1]. It is necessary to know the mean free-flow speed before an appropriate speed-flow relationship can be established and used as a basic for estimating capacity and level-of-service of any uninterrupted flow facilities [2]. The measured free-flow speed of individual vehicles can be determined either as a space-mean (harmonic mean) or as a time mean (arithmetic mean) [2]. However, Dowling [3] has stated that spacemean free-flow speed is normally used as the basic of many planning models to estimate average travel speeds and capacities.

Estimation of free-flow speed for ideal conditions may be based on either a known posted speed or a known 85th-percentile speed and free-flow speed may be estimated as $91 \%$ of the 85th-percentile speed for posted speed limits of $88.6 \mathrm{~km} / \mathrm{h}$ and $104.7 \mathrm{~km} / \mathrm{h}$ [4]. Moreover, Milliken [5] has also stated that the 85th-percentile speed is the speed at or below which $85 \%$ of drivers travel in free-flow conditions at representative locations on the highway or roadway section. However, in a study conducted by Deardoff et al. [6], in order to ensure that the freeflow speeds were collected in free-flow conditions, all speed observations were made at flow rates less than $500 \mathrm{veh} / \mathrm{h}$ and average headways of more than 7 seconds. In their study, they also mentioned that many other studies have used a 'rule of thumb' by adding $5 \mathrm{mi} / \mathrm{h}(10 \mathrm{~km} / \mathrm{h})$ above the posted limit to obtain free-flow speed without justification.

However, according to a study conducted by Bang et al. [7] to develop speed-flow relationships for rural roads in Indonesia, free-flow speed was determined for unobstructed vehicles based on the definition of vehicles with headway to the nearest vehicle in front of more than $8 \mathrm{~s}$ and no recent or immediate meeting with a vehicle in the opposing direction. Other studies by Chiguma [8], Ghani et al. [9], Al-Kaisy \& Karjala [10] and Ministry of Works Malaysia [11] also adopted the same headway threshold of 8 seconds. Meanwhile, other studies conducted by Tseng et al. [3], Figueroa \& Tarko [12], Gong and Stamatiadis [13], Himes and Donnell [14], Saifizul et al. [15] and Sekhar et al. [16] have measured the speed of free-flow vehicles based on time headways of 5 seconds while Silvano and Bang [17] have used headway threshold value of 10 seconds to measure free-flow speed. However, Wu et al. [18] have adopted a longer threshold value of 12 seconds to investigate the difference between free driving and car following.

Speed-density graph is another method which can be used to estimate free-flow speed. There are various types of speed-density graph such as Greenshield's model, Greenberg's model, Underwood's model, Drake's model and others. Speed-density models developed by Greenshield, Greenberg and Underwood are the more popular methods used to estimate freeflow speed. These models assumed that free-flow speed occurs when the driver could drive at any desirable speed at low density on a single roadway [19]. 
However, if field measurement of free-flow speed is not possible, free-flow speed can then be estimated indirectly based on the physical characteristics of the basic segment under studied. The physical characteristics include lane width, number of lanes, right shoulder lateral clearance and interchange density.

Ministry of Works Malaysia had attempted to study free-flow speed in Malaysia, as reported in the Traffic Study for Malaysia [2]. However, due to technological advancement and the surge of vehicles on roads, the values obtained in the study may not show the actual resemblance of current Malaysian traffic conditions. Therefore, a study of free-flow speed based on current Malaysian traffic conditions is needed. Findings of this study are valuable for local traffic engineers and highway authority in Malaysia for better understanding of the free-flow speed at basic segment expressways. Evidently, there are many studies conducted around the world to develop the free-flow speed models, but the suitability of these models for Malaysian traffic conditions is limited due to certain differences such as roadway characteristics, traffic composition and driver's behavior. Thus, free-flow speed model developed based on local traffic conditions is essential for the estimations of capacity and level-of-service at basic segment expressways in Malaysia.

\section{STUDY METHODOLOGY}

Field studies were conducted at various four-lane and six-lane basic segment expressways in Malaysia during typical working days such as Tuesday, Wednesday and Thursday using video recording method. Closed-circuit television (CCTV) camera mounted on a specially fabricated pole with a height of $1.5-\mathrm{m}$ was set up at a flyover, which is normally located at the midpoint of the basic segment expressway. The speed data were then converted to space-mean speed using the equation adopted from the Malaysian Highway Capacity Manual [20] as shown in equation (1).

$$
\bar{v}_{s}=1.021 \bar{v}_{t}-3.045
$$

where

$$
\begin{array}{lll}
\bar{v}_{t} & = & \text { Time mean speed } \\
\bar{v}_{s} & = & \text { Space-mean speed }
\end{array}
$$

Figure 1 shows the schematic diagram of the equipment setup. The Real-World Distance (RW Distance) was measured and marked on the road and set as $3.0 \mathrm{~m}$. The RW Distance is used as a reference to draw the region of interest (ROI) in the image processing software for vehicle detection. Data from the recorded video were then extracted using a commercial image processing software to obtain the desire traffic parameters such as volume, speed and headway. 
Leong L.V. and Muhammad H.

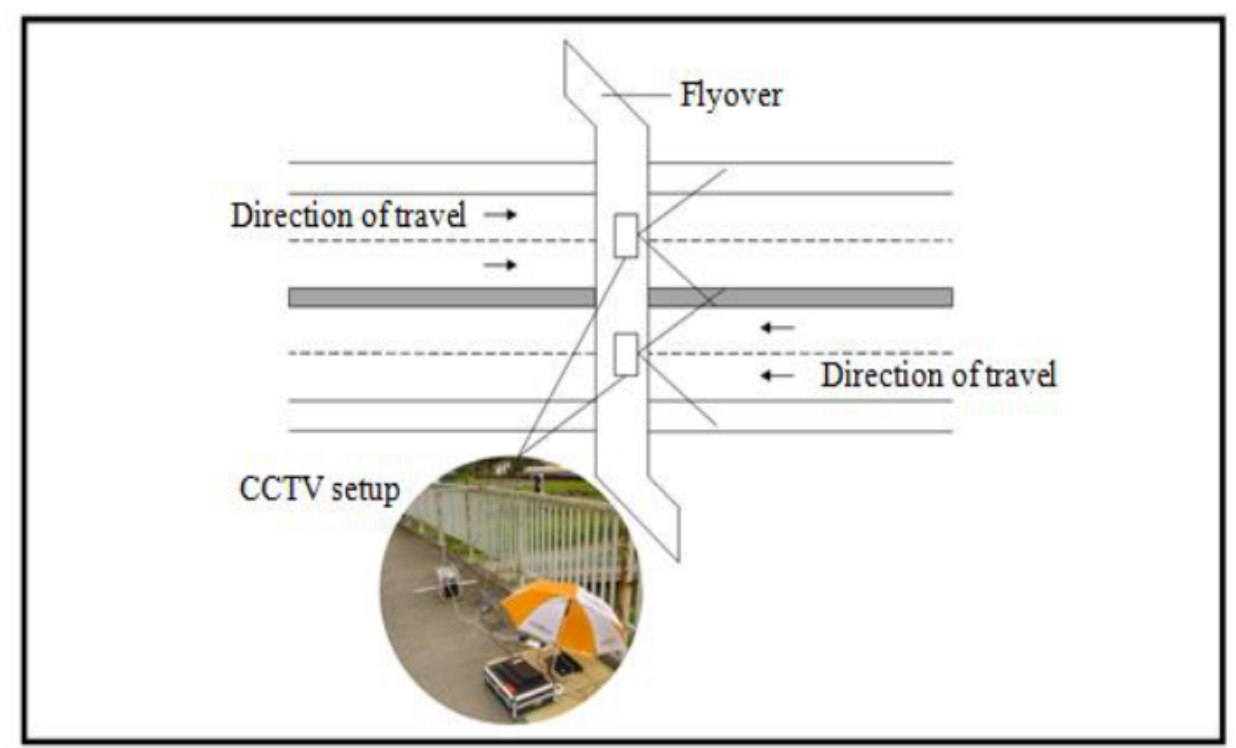

Figure 1 Equipment setup at flyover

In this study, free-flow speeds were computed for each individual lane based on three methods of measurements. In Method 1, free-flow speeds were computed by averaging speeds of all vehicles recorded during low to moderate traffic volume, up to $1,300 \mathrm{pc} / \mathrm{h} / \mathrm{ln}$ while in Method 2, free-flow speeds were determined based on the average speeds of vehicles with headways more than 8 seconds. Lastly, in Method 3, free-flow speeds were determined based on the speed-density plot. Multiple linear regression analyses were conducted to develop the free-flow speed estimation models and performance indicators, which include two error measures and three accuracy measures, were used to assess and select the most favorable model.

\section{DATA COLLECTION}

Data were collected during fine weather at 15 sites of four-lane, and two sites of six-lane basic segment expressways with level terrain in Perlis, Kedah, Perak, Selangor, Pahang and Terengganu. Traffic flows were recorded during peak and off-peak hours. During peak hours, traffic flows were recorded from 7:00 to 8:00 am and 5:30 to 6:30 pm while for off-peak hours, they were recorded from 10:00 am to $12: 00 \mathrm{pm}$ and 2:00 to $4: 00 \mathrm{pm}$.

The segment length of the expressway was fixed $10 \mathrm{~km}$ for each site and the location of data collection should be at least $1 \mathrm{~km}$ from any on-ramp or off-ramp in order to eliminate the effects of vehicles stopping or slowing down due to merging and diverging influence at onramp and off-ramp.

Roadway characteristics such as lane width, shoulder width, median clearance and interchange density were recorded by physical measurement in this study. All values of roadway characteristics were measured at least three spots along the segment (at downstream, midpoint and upstream) and the average value for each site is used for analysis. Table 1 shows the summary of roadway characteristics measured at all sites. 
Impact of Measurement Methods on the Development of Free-Flow Speed Estimation Model for Basic Segment Expressways in Malaysia

Table 2 Summary of road characteristics

\begin{tabular}{lccc}
\hline \multicolumn{1}{c}{ Statistics } & $\begin{array}{c}\text { Lane width } \\
(\mathbf{m})\end{array}$ & $\begin{array}{c}\text { Shoulder width } \\
(\mathbf{m})\end{array}$ & $\begin{array}{c}\text { Interchange density } \\
(\mathbf{/ k m})\end{array}$ \\
\hline No. of data & 72 & 72 & 72 \\
Minimum & 3.60 & 2.60 & 0.70 \\
Maximum & 4.10 & 5.30 & 1.70 \\
Mean & 3.8611 & 3.1042 & 1.0889 \\
Std. error of mean & 0.01111 & 0.07220 & 0.03687 \\
Std. deviation & 0.09428 & 0.61265 & 0.31289 \\
\hline
\end{tabular}

\section{RESULTS AND DISCUSSION}

\subsection{Comparative Analyses of Free-Flow Speed Based on Measurement Methods}

Based on the results obtained, free-flow speeds determined from the speed-density plots in Method 3 were much higher as compare to free-flow speeds measured using Methods 1 and 2, with standard deviation of around $11 \mathrm{~km} / \mathrm{h}$ recorded for all three methods. Table 2 shows the descriptive statistics calculated for free-flow speeds based on both method of measurements.

Table 2 Descriptive statistics of free-flow speeds based on measurement method

\begin{tabular}{|c|c|c|c|c|c|c|c|c|}
\hline \multirow[b]{2}{*}{ Method } & \multirow[b]{2}{*}{$\mathbf{N}$} & \multirow[b]{2}{*}{ Mean } & \multirow{2}{*}{$\begin{array}{c}\text { Std. } \\
\text { deviation }\end{array}$} & \multirow{2}{*}{$\begin{array}{l}\text { Std. } \\
\text { error }\end{array}$} & \multicolumn{2}{|c|}{ 95\% C.I. } & \multirow[b]{2}{*}{ Min. } & \multirow[b]{2}{*}{ Max. } \\
\hline & & & & & $\begin{array}{l}\text { Lower } \\
\text { bound }\end{array}$ & $\begin{array}{l}\text { Upper } \\
\text { bound }\end{array}$ & & \\
\hline 1 & 72 & 95.7415 & 11.30185 & 1.33194 & 93.0857 & 98.3973 & 73.68 & 119.21 \\
\hline 2 & 72 & 96.5831 & 11.18811 & 1.31853 & 93.9540 & 99.2121 & 73.76 & 120.06 \\
\hline 3 & 72 & 104.8471 & 11.04114 & 1.30121 & 102.2525 & 107.4416 & 74.41 & 125.15 \\
\hline
\end{tabular}

Further investigation was conducted to assess the free-flow speeds obtained from each method using one-way ANOVA. Based on the results shown in Table 3, the observed significant level which is less than 0.05 indicated that null hypothesis was rejected and therefore, can be concluded that the means of free-flow speed based on the three measurement methods were significantly different. Subsequently, upon knowing that the means of free-flow speeds were significantly, post hoc test was then conducted to determine which means differ. However, before the post hoc test can be conducted, Levene's test of homogeneity of variance must be conducted to check the equality of variance. Table 4 shows the results obtained from Levene's test of homogeneity of variance.

Table 3 One-way ANOVA for free-flow speed based on measurement method

\begin{tabular}{lccccc}
\hline & Sum of squares & df & Mean square & F & $\boldsymbol{p}$-value \\
\hline Between groups & 3834.586 & 2 & 1917.293 & 15.217 & $p<0.001$ \\
Within groups & 26838.136 & 213 & 126.001 & & \\
Total & 30672.722 & 215 & & & \\
\hline
\end{tabular}

Based on the results obtained from Levene's test of homogeneity of variance in Table 4, the Levene statistic obtained is 0.039 with a significant value of 0.962 . Thus, at the 0.05 level, the null hypothesis of equal variances across the three measurements methods was not rejected. Hence, equal variances were assumed in the post hoc test. Table 5 shows the results obtained from post hoc test. 
Leong L.V. and Muhammad H.

Table 4 Levene's test of homogeneity of variance for one-way ANOVA

\begin{tabular}{cccc}
\hline Levene statistic & d.f.1 & d.f. 2 & $p$-value \\
\hline 0.039 & 2 & 213 & 0.962 \\
\hline
\end{tabular}

Therefore, based on the results obtained in Table 5, free-flow speed computed based on Methods 1 and 2 were not significantly different from each other but they are significantly different than the values computed based on Method 3. Moreover, due to the reason that speeddensity graphs yield poor fit with values of coefficient of determination, $\mathrm{R}^{2}$ obtained very small, with value less than 0.5 for most sites, only free-flow speeds measured using Methods 1 and 2 were used for subsequent analysis.

Table 5 Post hoc test for free-flow speed based on measurement method

\begin{tabular}{llcc}
\hline \multicolumn{1}{c}{ Method } & \multirow{2}{*}{$\mathbf{N}$} & \multicolumn{2}{c}{ Subset for alpha $=\mathbf{0 . 0 5}$} \\
\cline { 3 - 4 } & 72 & 95.7415 & $\mathbf{2}$ \\
\hline Flow rate $(\leq 1,300 \mathrm{pc} / \mathrm{h} / \mathrm{ln})$ & 72 & 96.5861 & \\
Headway $(\geq 8 \mathrm{~s})$ & 72 & & 105.0718 \\
Speed-flow-density relationship & & 0.652 & 1.000 \\
\hline$p$-value & &
\end{tabular}

\subsection{Free-Flow Speed Models Using Multiple Linear Regression}

In this study, only two models using two different measurement methods of free-flow speeds were developed using multiple regression. The models as described below, were then assessed using performance indicators to select the best free-flow speed model basic segment expressways in Malaysia.

- Model 1 - based on average free-flow speed measured during low to moderate traffic flow of less than $1,300 \mathrm{puc} / \mathrm{h} / \mathrm{ln}($ Method 1$)$

- Model 2 - based on average free-flow speeds of vehicles with headways $\geq 8$ s (Method 2)

In order to develop the regression equation for free-flow speed, ideal conditions must first be determined. According to U.S. HCM 2010 [1], ideal conditions are assumed as a set of geometric and traffic conditions used as a starting point for computations of capacity and levelof-service. If any of these conditions fails to exist, the speed, level-of-service and capacity of the expressway segment will be reduced. Aside from good weather, good visibility and no incidents or accidents, the ideal geometric conditions for basic segment expressways based on Guideline for Malaysia Toll Expressway System - Design Standard which was published by Malaysian Highway Authority [21] are as follows:

- Lane width greater than or equal to $3.75 \mathrm{~m}$

- Shoulder width greater than or equal to $3.0 \mathrm{~m}$

- Median clearance wider than or equal to $1.0 \mathrm{~m}$

- Minimum interchange spacing of $5 \mathrm{~km}$ (in rural areas)

- Level terrain

Initially, the values of free-flow speed obtained were investigated based on lane positions. The results obtained show that all values of free-flow speed obtained at inner lane (median lane or fast lane) were higher than those obtained at outer lane. However, based on results obtained for six-lane expressways, free-flow speeds recorded at middle lanes were very near to the freeflow speeds recorded at inner lane. Nevertheless, a dummy variable indicating lane position was included in the regression model. However, following the rule that the number of dummies 
be one less than the number of categories of the variable, two dummy variables were needed for 3 categories of variable.

The results obtained from multiple linear regressions for Models 1 and 2 are as shown in equations (2) with $\mathrm{R}^{2}$ of 0.890 and equation (3) with $\mathrm{R}^{2}$ of 0.891 respectively. However, due to the reason that all surveyed sites have level terrain, the effect of gradient will not be included in the regression equations. Table 6 shows the summary of regression for free-flow speed models.

Model $1\left(\boldsymbol{R}^{2}=0.890\right)$ :

$F F S=B F F S-69.916(3.75-L W)-44.657(3.0-S H$ or $1.0-M C)-$ $105.118(I D)-21.557(L D 1)-14.023(L D 2)$

Model $2\left(\mathrm{R}^{2}=0.891\right)$ :

$F F S=B F F S-63.959(3.75-L W)-42.400(3.0-S H$ or $1.0-M C)-98.424(I D)-$ $21.625(L D 1)-13.340(L D 2)$

where

$\begin{array}{lll}F F S= & \text { Free-flow speed }(\mathrm{km} / \mathrm{h}) \\ B F F S= & \text { Base free flow speed }(\mathrm{km} / \mathrm{h}) \\ L W= & \text { Lane width (ideal lane width }=3.75 \mathrm{~m}) \\ S H= & \text { Shoulder width (ideal shoulder width }=3.0 \mathrm{~m}) \\ M C= & \text { Median clearance (ideal median clearance }=1.0) \\ I D= & \text { Interchange density } \\ L D 1= & \text { Lane dummy } 1(1 \text { if outer lane, } 0 \text { if otherwise) } \\ L D 2= & \text { Lane dummy } 2(\text { if center lane, } 0 \text { if otherwise) }\end{array}$

However, multiple linear regression requires several assumptions to be satisfied to obtain the best model with efficient, unbiased and consistent estimation. The four assumptions for residuals (error term) as follows:

- Mean of residual is zero

- Variance of residual is constant

- Residuals follow a normal distribution

- Residuals are uncorrelated with the independent variables

Residual analyses were then conducted to check these assumptions. Normal probability plot is a graphical technique used for assessing whether a data set is approximately normally distributed or otherwise. If the error terms are normally distributed, the points cluster around a $45^{\circ}$ straight line. However, if normal probability plot shows uncertainty in the normality assumptions, Kolmogorov-Smirnov (K-S) test can be used to assess the normality of the residuals. It used to test the null hypothesis that the residuals are from a normal distribution.

The normal probability plot generated for Models 1 and 2 using a statistical software are as shown in Figure 2. The results indicated that some of the data points deviate quite far from the $45^{\circ}$ straight line. Hence, the normality assumption might not be satisfied for these models and another test of normality, namely K-S test was then conducted to check on the normality assumption. Results from the K-S test with p-values greater than 0.05 indicated that the null hypothesis is not rejected, and hence, the residuals are normally distributed for both models and the normality assumption for each model is satisfied. 


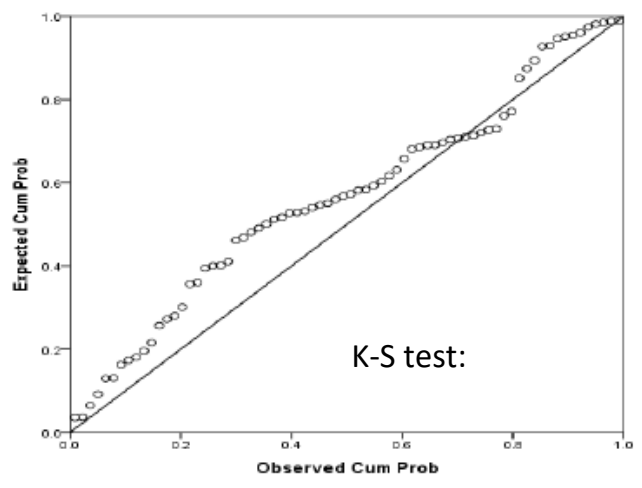

(a)

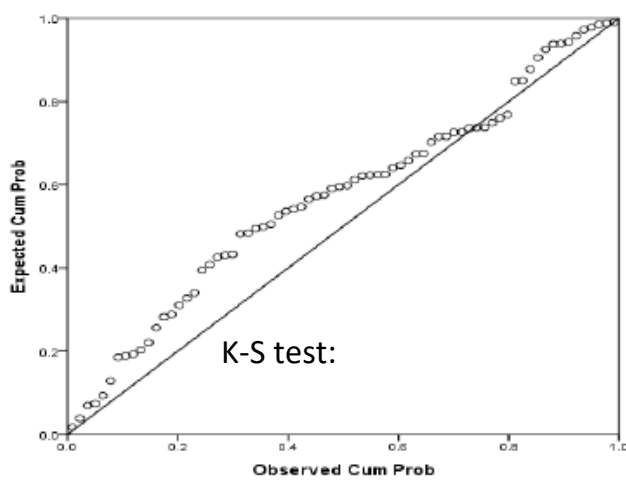

(b)

Figure 2 Normal probability plot generated for free-flow speed models (a) Model 1 (b) Model 2

Subsequently, the assumption of equal variance of errors was checked by assessing the distribution pattern of the residuals which was plotted against the fitted values. Figure 3 shows the residuals against fitted values plotted for both free-flow speed models. As shown in Figure 8 , the residuals plotted for both models appeared to be randomly scattered around the horizontal axis and this indicate that the assumptions of residuals to have a mean of zero and uncorrelated residuals with independent variables are reasonable.

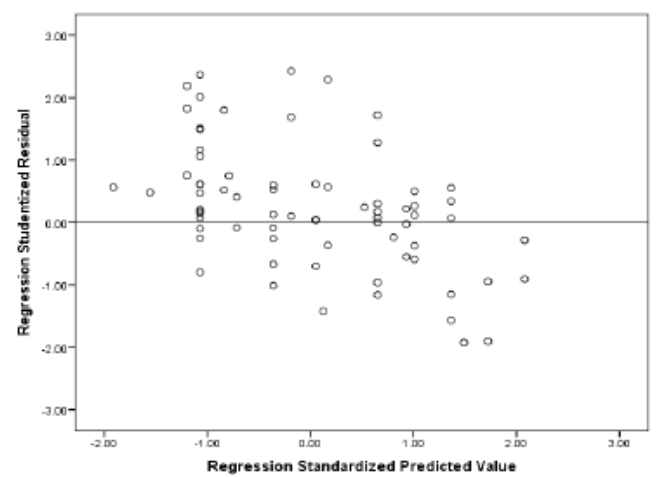

(a)

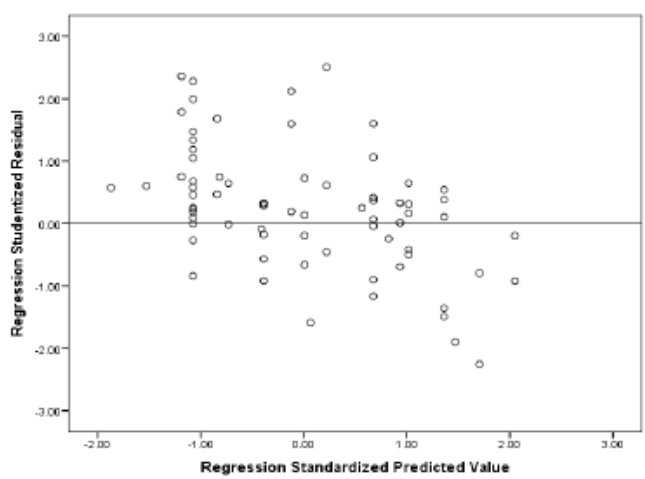

(b)

Figure 3 Residuals against fitted values for free-flow speed models (a) Model 1 (b) Model 2

Consequently, five performance indicators (PI), namely the Normalized Absolute Error (NAE), Root Mean Square Error (RMSE), Index of Agreement (IA), Prediction Accuracy (PA) and Coefficient of Determination $\left(\mathrm{R}^{2}\right)$ were used to assess the accuracy of the free-flow speed models. As smaller values of RMSE and NAE which are closer to zero are desired, score 1 will be given to each indicator that has the highest value. As for the measures of accuracy, higher values of PA, IA and $\mathrm{R}^{2}$, with values nearer to 1 are needed for the model to predict well. Therefore, score 1 will be given to each indicator that has the lowest value. The total score for each model is then calculated by adding the scores obtained in each PI and can be in the range between 5 to 10 . Total score of 5 is obtained when each of the performance indicator only obtained the minimum score of 1 while total score of 10 is obtained when each of the five indicators obtained the maximum score of 2 . The results are summarized in Table 6 . Based on the results shown in Table 3, Model 1 has the lowest score of 5 while Model 2 has the highest score of 10. Therefore, evidently, the choice of the best model will be Model 2. The selection of Model 2 as the best model also inferred that the most suitable measurement method of freeflow speed will be based on headways $\geq 8 \mathrm{~s}$. 
Impact of Measurement Methods on the Development of Free-Flow Speed Estimation Model for Basic Segment Expressways in Malaysia

Table 6 Summary of PI values for free-flow speed models

\begin{tabular}{cccccccc}
\hline \multicolumn{2}{c}{ Model } & NAE & RMSE & IA & PA & R $^{2}$ & \multirow{2}{*}{ Total score } \\
\hline \multirow{2}{*}{1} & Value & 0.0744 & 9.520 & 0.824 & 0.705 & 0.8904 & \multirow{2}{*}{5} \\
\cline { 2 - 8 } & Score & 1 & 1 & 1 & 1 & 1 & \multirow{2}{*}{10} \\
& Value & 0.0724 & 9.229 & 0.831 & 0.716 & 0.8908 & \multirow{2}{*}{2} \\
\cline { 2 - 8 } & Score & 2 & 2 & 2 & 2 & 2 & \\
\hline
\end{tabular}

\section{CONCLUSIONS}

This study compares three different methods of free-flow measurements which include the average free-flow speeds of all vehicles recorded during low to moderate traffic volume, freeflow speeds that were determined based on the average speed of vehicles with of headway more than 8 seconds and free-flow speeds that were determined based on linear speed-density graphs. Post hoc test indicated that free-flow speed computed based on average free-flow speeds of all vehicles recorded during low to moderate traffic volume and free-flow speeds determined based on average speed of vehicles with headway more than 8 seconds were not significantly different, but they are significantly different with the free-flow speeds determined from speeddensity relationship. Additionally, due to the reason that speed-density graphs yield poor fit with values $\mathrm{R}^{2}$ less than 0.5 for most sites, only free-flow speeds measured based on average free-flow speeds of all vehicles recorded during low to moderate traffic volume and free-flow speeds determined based on the average speed of vehicles with of headway more than 8 seconds were used in the development of free-flow speed estimation models. Results from performance indicator analyses indicated that the free-flow speed based on average speed of vehicles with headway of more than 8 seconds is the best model to estimate the free-flow speed of basic segment expressways in Malaysia. Therefore, findings of this study would improve the field data collection method in measuring the free-flow speed at basic segment expressways and application of the free-flow speed model which was developed based on local driving and traffic conditions can provide better estimation of capacity and level-of-service for basic segment expressways in Malaysia.

\section{ACKNOWLEDGEMENTS}

The authors wish to express their sincere gratitude to Highway Planning Unit, Ministry of Works Malaysia for funding this study and School of Civil Engineering, Universiti Sains Malaysia for the support.

\section{REFERENCES}

[1] Transportation Research Board (2010). HCM 2010, Highway Capacity Manual (2010). National Academy of Sciences, United States of America.

[2] Tseng, P., Lin, F., \& Shieh, S. L. (2005). Estimating of Free-Flow Speeds for Multilane Rural and Suburban Highways, 6, 1484 - 1495. DOI: 10.1016/j.trpro.2016.06.032

[3] Dowling, R. G. (Ed.). (1997). Planning techniques to estimate speeds and service volumes for planning applications, Vol. 387. Washington, D.C.

[4] Dixon, K. K., Wu, C., Sarasua, W., \& Daniel, J. (1999). Posted and Free -Flow Speeds for Rural Multilane Highways in Georgia. Journal of Transportation Engineering, 125 (November/December), $487-494$.

[5] Milliken, G. M. (1998). Managing Speed: Review of Current Practice for Setting and Enforcing Speed Limits. Transportation Research Board Special Report 254. Washington, D.C. 
[6] Deardoff, M. D., Wiesner, B. N., \& Fazio, J. (2011). Estimating Free-flow Speed from Posted Speed Limit Signs. Procedia Social and Behavioral Sciences, 16, 306 - 316. DOI: 10.1016/j.sbspro.2011.04.452.

[7] Bang, K. L., Carlsson, A., \& Palgunadi. (1996). Development of speed-flow relationships for Indonesian rural roads using empirical data and simulation. Transportation Research $\begin{array}{llllll}\text { Record, } & 1484, & 24 & - & 32 . & \text { Retrieved }\end{array}$ http://onlinepubs.trb.org/Onlinepubs/trr/1995/1484/1484-004.pdf

[8] Chiguma, M. L. M. (2007). Analysis of Side Friction Impact on Urban Road Links; Case Study Dar-es-salaam. Royal Institute of Technology Stockholm, Sweden.

[9] Ghani, A. R., Ibrahim, W. H., \& Sadullah, A. F. (2006). Penentuan hubungan laju-aliran lalu lintas jalan arteri. Jurnal Kejuruteraan, 117-133.

[10] Al-Kaisy, A., \& Karjala, S. (2008). Indicators of Performance on Two-Lane Rural Highway: Empirical Investigation. Journal of the Transportation Research Board, 2088, 8797. DOI:10.3141/2071-11

[11] Ministry of Works Malaysia. (1996). Traffic Study for Malaysia. Kuala Lumpur, Malaysia.

[12] Figueroa, A. M., \& Tarko, A. P. (2005). Speed Factors on Two-Lane Rural Highways in Free-Flow Conditions. Transportation Research Board, (1912), 39 - 46. Retrieved from https://doi.org/10.1177\%2F0361198105191200105

[13] Gong, H., \& Stamatiadis, N. (2008). Operating Speed Prediction Models for Horizontal Curves on Rural Four-Lane Highways. Transportstion Research Board, (2075), 1-7. DOI: $10.3141 / 2075-01$

[14] Himes, S. C., \& Donnell, E. T. (2010). Speed Prediction Models for Multilane Highways: Simultaneous Equations Approach. Journal of Transportation Engineering ASCE, (136), 855 - 862. Retrieved from https://doi.org/10.1061/(ASCE)TE.1943-5436.0000149.

[15] Saifizul, A. A., Yamanaka, H., \& Karem, M. R. (2011). Empirical Analysis of Gross Vehicle Weight and Free Flow Speed and Consideration on its Relation with Differential Speed Limit. Accident; analysis and prevention, 43 (3), 1068 - 1073. DOI: 10.1016/j.aap.2010.12.013

[16] Sekhar, C. R., Nataraju, J., Velmurugan, S., Kumar, P. \& Sitaramanjaneyulu, K. (2016). Free Flow Speed Analysis of Two Lane Inter Urban Highways. Transportation Research Procedia 17: 664-673. Retrieved from https://doi.org/10.1061/(ASCE)0733947X(1999)125:6(487).

[17] Silvano, A.P. \& Bang, K.L. (2016). Impact of Speed Limits and Road Characteristics on Free-Flow Speed in Urban Areas. Journal of Transportation Engineering, 142(2), 04015039-1 - 04015039-9. DOI: 10.1061/(ASCE)TE.1943-5436.0000800

[18] Wu, F., Jiang, J., Hu, W. L., \& Lu, J. (2011). Discerning Free Driving from Car-Following State Based on Trajectory Data from Active Mode Car-Following Experiment. Proceedings of the 11th International Conference of Chinese Transportation Professionals (ICCTP), 776 - 787. DOI: $10.1061 / 41186(421) 76$

[19] May, A.D. (1990). Traffic Flow Fundamentals. Prentice Hall.

[20] Highway Planning Unit, Ministry of Works Malaysia (2011). Malaysian Highway Capacity Manual 2011. ISBN 978-967-5399-21-3.

[21] Malaysian Highway Authority (2008). Guideline for Malaysia Toll Expressway System Design Standard.

[22] Rajendra Prasad A, Krishnaraj S, Ramachandran S (2017), Vasudevan N and Suresh S M. An Approach to the Development of a Green Energy Farm using Free Flow Horizontal Axis Water Turbine. International Journal of Mechanical Engineering and Technology, 8(7), 2017, pp. 25-36.

[23] G. Chiatti, O. Chiavola, E. Conti and E. Recco (2017), Automotive turbocharger speed estimation via vibration analYsis for combustion optimization, International Journal of Mechanical Engineering and Technology 8(10), 2017, pp. 153-163. 